\title{
Faktor-Faktor Penyebab Pekerjaan Ulang pada Pelaksana Konstruksi Anggota Gapensi di Kota Malang untuk Proyek Konstruksi
}

\author{
Dipa Supriyanti \\ Program Studi Teknik Sipil, Fakultas Teknik, Universitas Tribhuwana Tunggadewi \\ Jl. Telaga Warna Blok C, Tlogomas 65144 \\ e-mail : dipasupriyanti@yahoo.co.id. HP. 0821.3241.8009
}

\begin{abstract}
ABSTRAK
Proyek konstruksi dalam pelaksanaannya melibatkan banyak pihak yang terkait. Pihak-pihak yang terkait langsung adalah pemilik proyek (owner), Perencana Konstruksi, Pengawas Konstruksi dan Pelaksana Konstruksi. Dengan banyaknya pihak yang terlibat dalam proyek konstruksi, maka kerjasama yang terorganisir sangat diperlukan agar sasaran proyek yaitu biaya, mutu dan waktu dapat tercapai kerjasama tersebut tidak terjalin dengan baik, akan berpotensi menimbulkan pekerjaan ulang selama proyek tersebut berlangsung yang pada akhirnya akan berpengaruh terhadap biaya langsung dan tidak langsung. Pekerjaan ulang merupakan kegiatan dalam proyek selama masa konstruksi di lapangan yaitu paling sedikit satu kali atau lebih banyak karena ketidaksesuaian dengan permintaan. Pekerjaan ulang bisa terjadi pada semua jenis proyek konstruksi yaitu bangunan gedung, air dan transportasi. Dalam penelitian ini diteliti tentang faktor yang paling dominan yang menyebabkan pekerjaan ulang, ditinjau dari faktor perencanaan, pengawasan dan manajerial, dan sumber daya Pelaksana Konstruksi. Penelitian dilakukan dengan metode survei pada 29 sampel Pelaksana Konstruksi anggota Gapensi di Kota Malang. Faktor-faktor yang menyebabkan terjadinya pekerjaan ulang yang paling dominan dianalisa dengan menggunakan F-test dan t-test dengan tingkat signifikansi sebesar $10 \%$. Selain itu penelitian yang ditujukan untuk mengetahui jenis kontrak yang digunakan pada waktu mengalami pekerjaan ulang dan jenis pekerjaan yang paling berpotensi mengalami pekerjaan ulang. Analisa deskriptif dalam penelitian ini untuk memperlihatkan hasil berupa bobot terbesar di antara variabelvariabel yang diteliti, ditinjau dari tingkat frekuensi kejadiaannya. Analisa F-test memberikan hasil faktor pengawasan dan manajerial merupakan penyebab utama terjadinya pekerjaan ulang yang signifikan ( $\mathrm{P}-$ value $=0.4644$ ) dengan taraf signifikansi $\alpha=10 \%$.
\end{abstract}

Kata kunci : proyek; konstruksi; pekerjaan ulang

\section{ABSTRACT}

There are many element involved in a construction project. Some element that directly connected is the project owner itself, construction planner, constructor executor and the constructor executive. With so many element involved in construction project then organized teamwork is very needed so the project target including the cost, quality and time can be reached successfully. If the teamwork not running well, then it patented to create the rework during the project that finally at least can be affected to the one time direct and undirect cost. Rework is an activity in the project during the construction time in the field that usually happen at least one time or even more that can be bappened because there is unmatch jobs according to the demand. Rework could happen in any kind of construction project, whether building, watering and transportation construction. This research is observing about the most dominant factor that can causes rework, viewing from the planning, execution, managerial and the contractor sources factor. Research done by surveying method for 29 samples of Gapensi constructor executive member in Malang. Factors that causes the rework are analized using the F-test and $T$ test with significant level as big as $10 \%$. Another that, the research are also purposed to known the kinds of contract that usually used when the rework happen and kind of jobs that mostly potential for rework. 
Descriptive analize in this research to show the biggest level between the variables that researching, viewing from the frequently level. F-test analiring result shows that the executor and managerial are the factors that can causes rework that significant $(P$-value $=0.4644$ ) with significant level of $a=10 \%$. T-test analizing give result to each grup, the factor that mostly get the rework. The group that very often doing the rework at planning factor are the design changing by the project owner (P-value 0.023) with $10 \%$ significant level. The group that very often doing the rework at executor and managerial factors is the unwell teamwork between the project owner, constructor planner, constructor executor and constructor executive (P-value $=0.1748)$ for $10 \%$ significant level. The group that mostly very often doing the rework at contactor sources factor are the unexperience worker (P-value $=0.9378)$ for $10 \%$ significantly level.

Keywords : project; construction; rework

\section{PENDAHULUAN}

Anggapan utama yang menyebabkan terjadinya pekerjaan ulang pada proyek konstruksi adalah kurangnya komunikasi antara pihak-pihak yang terlibat dalam proyek konstruksi yaitu Pemilik Proyek, Perencana Konstruksi, Pengawas Konstruksi dan Pelaksana Konstruksi. Perencanaan konstruksi yang salah, kurangnya informasi dari Perencana Konstruksi kepada Pelaksana Konstruksi, pelaksanaan yang tidak sesuai dengan bestek, hingga metode pelaksanaan yang tidak sesuai. Kesalahan-kesalahan tersebut tidak seharusnya terjadi apabila komunikasi antara pihak-pihak yang terlibat dalam proyek konstruksi terjalin dengan baik sehingga tidak meyebabkan terjadinya pekerjaan ulang.

Pekerjaan ulang adalah mengerjakan sesuatu paling sedikit satu kali lebih banyak, yang disebabkan oleh ketidakcocokkan dengan permintaan [1]. Mengulang pekerjaan menyebabkan keterlambatan pelaksanaan proyek di lapangan. Karena dengan mengulang pekerjaan yang telah dikerjakan, maka akan terjadi penambahan waktu dalam penyelesaian proyek tersebut.

Beberapa penelitian mengungkapkan bahwa biaya yang ditimbulkan sebagai akibat dari pekerjaan ulang cukup signifikan. Dalam penelitian pada 9 (sembilan) proyek, disebutkan bahwa biaya rata-rata yang dikeluarkan untuk memperbaiki masalah kualitas adalah 12,4\% dari nilai kontrak [2]. Sementara itu, penelitian lain bahkan menemukan biaya karena kegagalan kualitas mencapai $25 \%$. Selain biaya langsung, pekerjaan ulang juga membawa dampak pada biaya tidak langsung, biaya-biaya administrasi seperti overhead.

Pekerjaan ulang adalah aktivitas di lapangan yang harus diselesaikan lebih dari satu kali di lapangan atau menghilangkan pekerjaan sebelumnya yang telah dilakukan di mana tidak ada permintaan perubahan dari pemilik proyek sebelum pekerjaan tersebut telah terealisasi di lapangan dan diperlukan waktu dalam proses peniadaannya [3].

Faktor-faktor penyebab pekerjaan ulang dikelompokkan menjadi 3 bagian, yaitu : faktor perencanaan, pengawasan dan manajerial, dan sumber daya Pelaksana Konstruksi [4]. Faktor-faktor tersebut dibagi menjadi beberapa faktor sebagai berikut :

1. Faktor Perencanaan

- Kesalahan desain

- Perubahan desain

- Detail tidak jelas

- Kurangnya pengetahuan tentang karakter bahan

- Buruknya koordinasi dokumen

2. Faktor Pengawasan dan Manajerial

- Jadwal yang terlalu padat

- Kurangnya kontrol 
- Kurangnya teamwork

- Kurangnya informasi lapangan

- Material salah kirim

- Material terlambat

- Buruknya alur informasi

- Kurangnya antisipasi terhadap keadaan alam

3. Faktor Sumber Daya Pelaksana Konstruksi

- Pekerja kurang berpengalaman

- Pekerja kurang pengetahuan

- Banyaknya kerja lembur

- Salah metode kerja

- Salah keputusan

- Kurangnya peralatan

Berdasarkan rumusan masalah, tujuan dan kerangka pemikiran yang telah dirumuskan maka model hipotesis dalam penelitian ini adalah sebagai berikut :

- Ho : Tidak ada variabel yang dominan menyebabkan pekerjaan ulang.

- Hi : Ada variabel yang dominan menyebabkan pekerjaan ulang.

\section{METODE PENELITIAN}

Berdasarkan tujuannya, penelitian ini adalah jenis explanatory research. Yang bertujuan untuk meningkatkan pemahaman tentang sebuah fenomena yang telah diketahui. Berdasarkan tingkat eksplanasinya, penelitian yang dilakukan adalah deskriptif. Data deskriptif pada umumnya dikumpulkan melalui daftar pertanyaan dalam survei, wawancara ataupun observasi [5]. Menurut analisa yang dilakukan, jenis data yang diperoleh termasuk data kuantitatif dan kualitatif. Data kuantitatif adalah data yang diukur dalam suatu skala numerik (angka), sedangkan data kualitatif adalah mengklasifikasikan data dalam bentuk kategori [6].
Berdasarkan rumusan dari Love dan adaptasi Penulis dari berbagai sumber, di dapat variabel-variabel yang menyebabkan pekerjaan ulang, yaitu : Faktor Perencanaan Kesalahan desain oleh Perencana Konstruksi, Perubahan desain dari Pemilik Proyek, Detail gambar tidak jelas, Kurangnya pengetahuan Perencana Konstruksi tentang karakter bahan, Buruknya koordinasi dokumen), Faktor Pengawasan dan Manajerial (Kurangnya teamwork antara Pemilik Proyek, Perencana Konstruksi, Pengawas Konstruksi dan Pelaksana Konstruksi, Kurangnya informasi lapangan, Kurangnya kontrol dari Pemilik Proyek dan Pengawas Konstruksi, Buruknya alur informasi, Jadwal yang terlalu padat, Ketidakpastian kondisi politik, Kelangkaan material, Material terlambat dating, Material dari supplier tidak sesuai dengan spesifikasi teknis, Kurangnya antisipasi terhadap perubahan cuaca), Faktor Sumber Daya Pelaksana Konstruksi (Pekerja kurang berpengalaman, Pekerja mengerjakan pekerjaan yang tidak sesuai dengan keahliannya, Banyaknya kerja lembur, Metode pelaksanaan yang tidak sesuai, Salah dalam mengambil keputusan, Kurangnya peralatan, Peralatan yang dipakai sudah tidak layak pakai).

Unit analisa merupakan sesuatu yang diteliti. Dalam penelitian ini, unit analisanya adalah proyek Pelaksana Konstruksi anggota Gapensi di Kota Malang yang pernah mengalami pekerjaan ulang dalam kurun waktu 2 tahun terakhir. Lokasi penelitian dilakukan di Kota Malang pada Pelaksana Konstruksi anggota Gapensi yang pernah mengalami pekerjaan ulang.

Populasi dalam penelitian ini adalah seluruh Pelaksana Konstruksi anggota Gapensi di Kota Malang yang pernah mengalami pekerjaan ulang. 
Pelaksana Konstruksi yang menjadi sampel dalam penelitian ini dipilih melalui survei pendahuluan. Survei pendahuluan bertujuan untuk memastikan apakah Pelaksana Konstruksi tersebut pernah mengalami pekerjaan ulang atau tidak. Dari survei tersebut diperoleh 25 sampel Pelaksana Konstruksi di Kota Malang yang pernah mengalami pekerjaan ulang. Adapun perincian sampel tersebut dapat dilihat pada Tabel 1 berikut :

\section{Tabel 1. Sampel Pelaksana Konstruksi}

\begin{tabular}{ccc}
\hline Golongan & $\begin{array}{c}\text { Populasi } \\
\text { Pelaksana } \\
\text { Konstruksi }\end{array}$ & $\begin{array}{c}\text { Sampel } \\
\text { Pelaksana } \\
\text { Konstruksi }\end{array}$ \\
\hline Kecil & 58 & 20 \\
\hline Menengah & 5 & 5 \\
\hline Jumlah & 63 & 25 \\
\hline
\end{tabular}

Data-data yang digunakan dalam penelitian ini adalah data primer dan sekunder. Data primer dalam penelitian ini adalah hasil kuesioner dan wawancara dengan Pelaksana Konstruksi yang dipilih sebagai sampel. Data sekunder merupakan data primer yang telah diolah lebih lanjut. Data sekunder dalam penelitian ini adalah sebagai berikut :

- Pendapat para peneliti tentang pekerjaan ulang.

- Hasil penelitian para peneliti tentang penyebab pekerjaan ulang di lapangan.

Kuesioner merupakan cara pengumpulan data dengan memberikan daftar pertanyaan kepada responden untuk diisi [7]. Dalam penelitian ini, satu kuesioner berlaku untuk satu Pelaksana Konstruksi, sehingga jumlah kuesioner adalah 25 berkas. Penyebaran kuesioner dilakukan dengan cara penyampaian langsung kepada responden.
Pertanyaan kuesioner dalam penelitian ini dibagi menjadi 8 (delapan) bagian dengan menggunakan skala. Dari penjelasan bab sebelumnya, maka tipe skala yang digunakan dalam penelitian ini adalah skala dikotomi dan skala likert dengan menggunakan 5 poin skala yaitu sangat jarang, jarang, kadangkadang, sering dan sangat sering.

Untuk menguji hipotesis dalam penelitian ini, prosedur pengujiannya adalah sebagai berikut :

1. Menyatakan hipotesisnya

Hipotesis dapat dinyatakan dalam bentuk nol (null bypothesis) atau alternative (alternative bypothesis) [8]. Dalam penelitian ini, hipotesis nol menyatakan bahwa tidak ada perbedaan antara pendapat Pelaksana Konstruksi kualifikasi kecil dan menengah, sedang hipotesis alternative menyatakan bahwa ada perbedaan antara pendapat Pelaksana Konstruksi kecil dan menengah.

2. Memilih pengujian statistiknya

Dalam penelitian ini, uji statistik yang digunakan adalah F-test dan T-test.

3. Menentukan tingkat keyakinan yang diinginkan

Dalam penelitian ini, tingkat keyakinan yang digunakan adalah $\alpha=10 \%$.

4. Menghitung nilai statistiknya

5. Mendapatkan nilai uji kritis

6. Menyimpulkan hasil

Dengan membandingkan $\mathrm{t}$ tabel dan $\mathrm{t}$ hitung, maka :

- Jika $\mathrm{t}$ hitung $>\mathrm{t}$ tabel, maka Ho ditolak

- Jika t hitung $\leq \mathrm{t}$ tabel, maka Ho diterima

Dengan melihat nilai probabilitas (Pvalue), maka :

- Jika P-value $\leq 0.10$, maka $\mathrm{H}_{0}$ ditolak

- Jika P-value $>0.10$, maka $\mathrm{H}_{0}$ diterima 
Bagan alir penelitian ini dapat dilihat pada Gambar 3.1. Pelaksanaan dalam penelitian tentang pekerjaan ulang ini

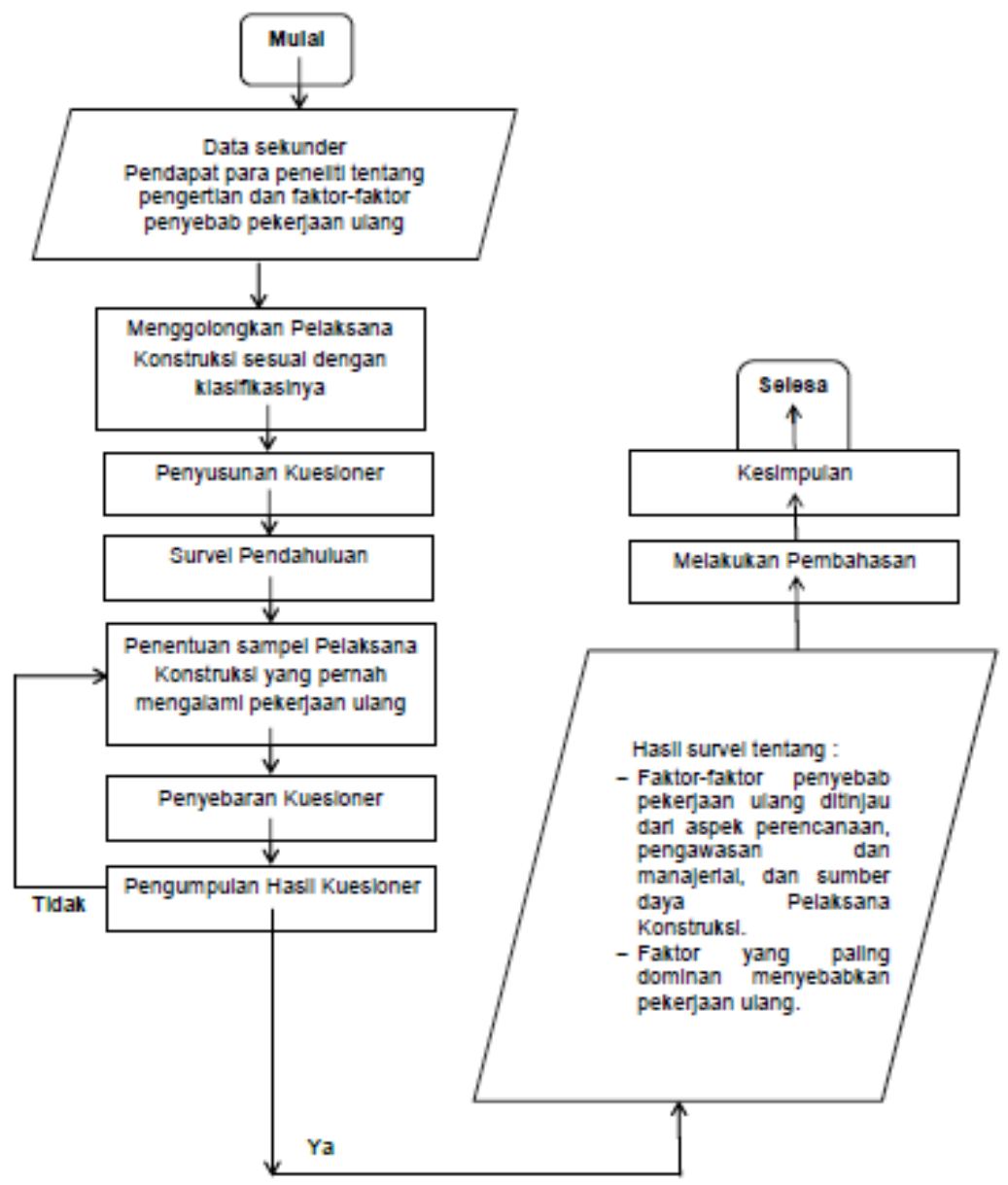

Gambar 1. Bagan Alir Penelitian terdiri atas beberapa langkah sebagai berikut : 


\section{Berdasarkan Jenis Kontrak}

Analisa Hasil

Hipotesis

$\mathrm{H}_{0}$ : tidak ada perbedaan antara pendapat Pelaksana Konstruksi kualifikasi kecil dan menengah bahwa pekerjaan finishing paling sering menyebabkan pekerjaan ulang.

$\mathrm{H}_{1}$ : ada perbedaan antara pendapat Pelaksana Konstruksi kualifikasi kecil dan menengah bahwa pekerjaan finishing paling sering menyebabkan pekerjaan ulang.

$t$ tabel

$\mathrm{df}: \mathrm{n} 1+\mathrm{n} 2-2 \rightarrow 5+20-2=23$

Tingkat signifikansi adalah $10 \%$ atau menjadi $10 \% / 2=5 \%(\alpha=0.05)$ untuk uji dua sisi.

Untuk $\mathrm{t}(0.05,23)$ pada $\mathrm{t}$ tabel didapat angka 1.1714.

Jadi t kritis adalah -1.714 dan +1.714 untuk uji dua sisi.

\section{t hitung}

Dari hasil output Uji-t didapat hasil t hitung adalah 0.6197 .

\section{Pengambilan Keputusan :}

Dengan membandingkan $\mathrm{t}$ tabel dan $\mathrm{t}$ hitung, maka :

Jika t hitung $>$ t tabel, maka $\mathrm{H}_{0}$ ditolak Jika thitung $<\mathrm{t}$ tabel, maka $\mathrm{H}_{0}$ diterima Dengan melihat nilai probabilitas (P-value), maka :

Jika P-value $<0.10$, maka $\mathrm{H}_{0}$ ditolak

Jika $\mathrm{P}$-value $>0.10$, maka $\mathrm{H}_{0}$ diterima

\section{Kesimpulan}

Dengan membandingkan $\mathrm{t}$ tabel dan $\mathrm{t}$ hitung, maka :

Karena t hitung $(+0.6197)<\mathrm{t}$ tabel $(+$ 1.174), maka $\mathrm{H}_{0}$ diterima atau tidak ada perbedaan pendapat antara Pelaksana Konstruksi kualifikasi kecil dan menengah bahwa pekerjaan finishing paling sering menyebabkan pekerjaan ulang.

\section{Faktor Perencanaan}

\section{Analisa Hasil}

\section{Hipotesis}

$\mathrm{H}_{0}$ : tidak ada perbedaan antara pendapat Pelaksana Konstruksi kualifikasi kecil dan menengah bahwa perubahan desain oleh Pemilik Proyek paling sering menyebabkan pekerjaan ulang.

$\mathrm{H}_{1}$ : ada perbedaan antara pendapat Pelaksana Konstruksi kualifikasi kecil dan menengah bahwa perubahan desain oleh Pemilik Proyek paling sering menyebabkan pekerjaan ulang.

\section{t tabel}

$\mathrm{df}: \mathrm{n} 1+\mathrm{n} 2-2 \rightarrow 5+20-2=23$

Tingkat signifikansi adalah $10 \%$ atau menjadi $10 \% / 2=5 \%(\alpha=0.05)$ untuk uji dua sisi.

Untuk $\left.t_{(0.05,23}\right)$ pada $t$ tabel didapat angka 1.1714.

Jadi t kritis adalah -1.714 dan +1.714 untuk uji dua sisi.

\section{t hitung}

Dari hasil output Uji-t didapat hasil t hitung adalah +0.421 .

\section{Pengambilan Keputusan :}

Dengan membandingkan $t$ tabel dan $t$ hitung, maka :

Jika t hitung $>$ t tabel, maka $\mathrm{H}_{0}$ ditolak

Jika t hitung $<\mathrm{t}$ tabel, maka $\mathrm{H}_{0}$ diterima

Dengan melihat nilai probabilitas (P-value), maka :

Jika $\mathrm{P}$-value $<0.05$, maka $\mathrm{H}_{0}$ ditolak

Jika P-value $>0.05$, maka $\mathrm{H}_{0}$ diterima

\section{Kesimpulan}

Dengan membandingkan $t$ tabel dan t hitung, maka :

Karena $\mathrm{t}$ hitung $(+0.421<\mathrm{t}$ tabel $(+1.174)$, maka $\mathrm{H}_{0}$ diterima atau tidak ada 
perbedaan pendapat antara Pelaksana Konstruksi kualifikasi kecil dan menengah bahwa perubahan desain oleh Pemilik Proyek paling sering menyebabkan pekerjaan ulang.

Dengan melihat nilai probabilitas ( $\mathrm{P}$-value), maka :

Karena P-value hasil output dari Uji-t adalah $0.685>0.05$, maka $\mathrm{H}_{0}$ diterima, atau tidak ada perbedaan pendapat antara Pelaksana Konstruksi kualifikasi kecil dan menengah bahwa perubahan desain oleh Pemilik Proyek paling sering mengalami pekerjaan ulang.

\section{Faktor Pengawasan dan Manajerial}

\section{Analisa Hasil}

\section{Hipotesis}

$\mathrm{H}_{0}$ : tidak ada perbedaan antara pendapat Pelaksana Konstruksi kualifikasi kecil dan menengah bahwa kurangnya teamwork antara Pemilik Proyek, Perencana Konstruksi, Pelaksana Konstruksi dan Pengawas Konstruksi paling sering menyebabkan pekerjaan ulang.

$\mathrm{H}_{1}$ : ada perbedaan antara pendapat Pelaksana Konstruksi kualifikasi kecil dan menengah bahwa kurangnya teamwork antara Pemilik Proyek, Perencana Konstruksi, Pelaksana Konstruksi dan Pengawas Konstruksi paling sering menyebabkan pekerjaan ulang.

\section{t tabel}

df $: \mathrm{n} 1+\mathrm{n} 2-2 \rightarrow 5+20-2=23$

Tingkat signifikansi adalah $10 \%$ atau menjadi $10 \% / 2=5 \%(\alpha=0.05)$ untuk uji dua sisi.

Untuk $\mathrm{t}(0.05,23)$ pada $\mathrm{t}$ tabel didapat angka 1.1714 .
Jadi t kritis adalah -1.714 dan +1.714 untuk uji dua sisi.

\section{t hitung}

Dari hasil output Uji-t didapat hasil t hitung adalah +1.40 .

\section{Pengambilan Keputusan :}

Dengan membandingkan $\mathrm{t}$ tabel dan $\mathrm{t}$ hitung, maka :

Jika t hitung $>$ t tabel, maka $\mathrm{H}_{0}$ ditolak Jika t hitung $<\mathrm{t}$ tabel, maka $\mathrm{H}_{0}$ diterima Dengan melihat nilai probabilitas (P-value), maka :

Jika P-value $<0.05$, maka $\mathrm{H}_{0}$ ditolak

Jika P-value $>0.05$, maka $\mathrm{H}_{0}$ diterima

\section{Kesimpulan}

Dengan membandingkan $t$ tabel dan t hitung, maka :

Karena $\mathrm{t}$ hitung $(+1.40)<\mathrm{t}$ tabel $(+1.174)$, maka $\mathrm{H}_{0}$ diterima atau tidak ada perbedaan pendapat antara Pelaksana Konstruksi kualifikasi kecil dan menengah bahwa kurangnya teamwork antara Pemilik Proyek, Perencana Konstruksi, Pelaksana Konstruksi dan Pengawas Konstruksi paling sering menyebabkan pekerjaan ulang.

\section{Faktor Sumber Daya Pelaksana} Konstruksi

Analisa Hasil

Hipotesis

$\mathrm{H}_{0}$ : tidak ada perbedaan antara pendapat Pelaksana Konstruksi kualifikasi kecil dan menengah bahwa pekerja kurang berpengalaman paling sering menyebabkan pekerjaan ulang.

$\mathrm{H}_{1}$ : ada perbedaan antara pendapat Pelaksana Konstruksi kualifikasi kecil dan menengah bahwa pekerja kurang berpengalaman paling sering menyebabkan pekerjaan ulang. 


\section{t tabel}

df $: \mathrm{n} 1+\mathrm{n} 2-2 \rightarrow 5+20-2=23$

Tingkat signifikansi adalah $10 \%$ atau menjadi $10 \% / 2=5 \%(\alpha=0.05)$ untuk uji dua sisi.

Untuk $\mathrm{t}(0.05,23)$ pada $\mathrm{t}$ tabel didapat angka 1.1714 .

Jadi t kritis adalah -1.714 dan +1.714 untuk uji dua sisi.

\section{t hitung}

Dari hasil output Uji-t didapat hasil t hitung adalah -0.0789 .

\section{Pengambilan Keputusan :}

Dengan membandingkan $t$ tabel dan t hitung, maka :

Jika t hitung $>\mathrm{t}$ tabel, maka $\mathrm{H}_{0}$ ditolak

Jika t hitung $<\mathrm{t}$ tabel, maka $\mathrm{H}_{0}$ diterima

Dengan melihat nilai probabilitas (P-value), maka :

Jika P-value $<0.05$, maka $\mathrm{H}_{0}$ ditolak

Jika $\mathrm{P}$-value $>0.05$, maka $\mathrm{H}_{0}$ diterima

\section{Kesimpulan}

Dengan membandingkan $t$ tabel dan t hitung, maka :

Karena t hitung $(-0.0789)<\mathrm{t}$ tabel (- 1.174), maka $\mathrm{H}_{0}$ diterima atau tidak ada perbedaan pendapat antara Pelaksana Konstruksi kualifikasi kecil dan menengah bahwa pekerja kurang berpengalaman paling sering menyebabkan pekerjaan ulang.

\section{KESIMPULAN}

Dari pembahasan yang telah dilakukan, maka dapat diambil kesimpulan sebagai berikut :

1. Ditinjau dalam kelompok faktor perencanaan, yang paling dominan menyebabkan pekerjaan ulang menurut Pelaksana Konstruksi kualifikasi kecil dan menengah adalah perubahan desain oleh Pemilik Proyek.
2. Ditinjau dalam kelompok faktor pengawasan dan manajerial, yang paling dominan menyebabkan pekerjaan ulang menurut Pelaksana Konstruksi kualifikasi kecil dan menengah adalah kurangnya teamwork antara Pemilik Proyek, Perencana Konstruksi, Pengawas Konstruksi dan Pelaksana Konstruksi.

3. Ditinjau dalam kelompok faktor sumber daya Pelaksana Konstruksi, yang paling dominan menyebabkan pekerjaan ulang menurut Pelaksana Konstruksi kualifikasi kecil dan menengah adalah pekerja kurang berpengalaman.

4. Ditinjau dalam kelompok faktor perencanaan, pengawasan dan manajerial, dan sumber daya Pelaksana Konstruksi, yang paling dominan menyebabkan pekerjaan ulang adalah faktor pengawasan dan manajerial yang paling banyak dipilih oleh Pelaksana Konstruksi kualifikasi kecil dan menengah.

\section{DAFTAR PUSTAKA}

[1] Peter Barda. 1995. The Construction Industry Development Agency. Issued by the Authority of the Assistant Minister for Industrial Relations

[2] Winata S., Hendarlim Y. 2005. FaktorFaktor Penyebab Rework Pada Pekerjaan Konstruksi. Dimensi Teknik Sipil Vol. 7, No. 1, 22-29,

[3] Fayek, AR. 2002. COAA (Construction Owners Association of Alberta) Measurement Sub-Committee.

[4] Love, Peter. 2002. Influence of Project Type and Procurement Method on Rework Cost in Building Construction Projects. Journal of Construction Engineering 
and Management. DOI: 10.1061

/(ASCE)0733-9364(2002)128:1(18)

[5] Kuncoro, Mudrajad. 2003. Metode Riset untuk Bisnis \& Ekonomi. Jakarta : Erlangga, 8.

[6] Kuncoro, Mudrajad. 2003. Metode Riset untuk Bisnis \& Ekonomi. Jakarta : Erlangga, 124.

[7] Arsyad, Lincolin, Soeratno. 2003. Metode Penelitian untuk Ekonomi dan Bisnis. Yogyakarta : Akademi Manajemen Perusahaan.

[8] Jogiyanto, 2004. Metodologi Penelitian Bisnis. Yogyakarta : BPFE Yogyakarta. 